\title{
SINTACS and DRASTIC Models for Groundwater Vulnerability Assessment and Mapping using a GIS and Remote sensing Techniques: a Case Study on Berrechid Plain
}

\author{
M. Aboulouafa ${ }^{1 *}$, H. Taouil ${ }^{1}$, S. Ibn Ahmed ${ }^{1}$, A. Tairi ${ }^{2}$, K. Arouya ${ }^{1}$, M. \\ hsaissoune ${ }^{3}$, \\ 1. Laboratory of Materials, Electrochemistry and Environment. Faculty of Sciences, \\ Département de Chimie, University Ibn Tofail Kénitra, Morocco. \\ 2. Département de Géologie faculté des sciences Ibn Zohr Agadir, Morocco. \\ 3. Département de Géologie faculté des sciences et techniques Béni Mellal, Morocco.
}

\begin{abstract}
Groundwater is a better resource for water requirements, its protection and management is vital for human evolution and ecological diversity. Agricultural and industrial activities have contributed to the degradation of the quality of Berrechid groundwater. The aim of this study is to evaluate and map the vulnerability of the Berrechid aquifer using the DRASTIC and SINTACS models and to compare between them. The application of this methodology requires a GIS synthesizing a mass of data (geological, hydrogeological, Geophysics, etc.), is a real decision-making tool for water resources managers in the Chaouia region. The two models show a low to average vulnerability, by overlaying the map of distribution of Nitrate on the two maps we find that the SINTACS model gives the best result with two classes of vulnerability (low and average): the most vulnerable areas are displayed in areas of low depth to the water table and the areas that are not protected by the clays, and areas less vulnerable are located in regions where the water is deeper and the clays recovery is important.
\end{abstract}

Key words: groundwater vulnerability, SINTACS, DRASTIC, pollution, Environment Berrechid plain.

\section{INTRODUCTION}

The Berrechid Basin is located in the south of Casablanca, between the Atlantic Ocean and the Phosphate Plateau (Figure 1). The total area is about $1600 \mathrm{~km}^{2}$. It is a tectonic basin with subsidence and sedimentation since the Triassic [1].The cover is made up of marine dune sandstone of the Pliocene [2] (Fig.1), its main aquifer is located between 5 and $30 \mathrm{~m}$ depth [3]. This groundwater has an underground hydraulic potential which represents the sole and unique water resource in the region; it is the source of the drinking water supply of a large part of the rural areas of the province and a part of Settat city. Berrechid City has known these past fifteen years a development of industrial and agricultural activities with a use of more and more exaggerated chemical fertilizers. Berrechid groundwater is generally of a very bad quality for the whole of the sampling points, because of its strong mineralization, elevated chloride and nitrate [4]. The prevention of groundwater pollution is an important step, to which scientists must deploy more effort, including the assessment of the groundwater vulnerability [1].Remote sensing and GIS are powerful tools that can be used in the collection and the combination of data [5]. They are our days as essential tools in the interactive systems to the decision aid [6].

\section{PRESENTATION OF THE STUDY AREA}

The Berrechid groundwater is located in the south of Casablanca, Morocco between the Atlantic Ocean and the Phosphate Plateau (fig 1); it is characterized by its important extent. The Berrechid plain is composed of sedimentary rocks formed Cretaceous limestone (Cenomanian) with intercalations of clays and marls and sedimentary rocks formed of calcareous sandstone to cemented conglomerates toward the base .The whole is surmounted by coverage of clayey silts of the recent quaternary. This part of the low Chaouia, receives of the upstream varied erosion elements from the high Chaouia (Plateau of Settat - Ben Ahmed) from which it is separated by the flexure of Settat [1].The annual precipitations average in Berrechid plain varies between 280 and $310 \mathrm{~mm} /$ year. The temperature presents wide variations between the winter and the summer, with $24.9^{\circ} \mathrm{C}$ as an average of the maxima and $9.6^{\circ} \mathrm{C}$ as an average of the minima (ABHBC). 


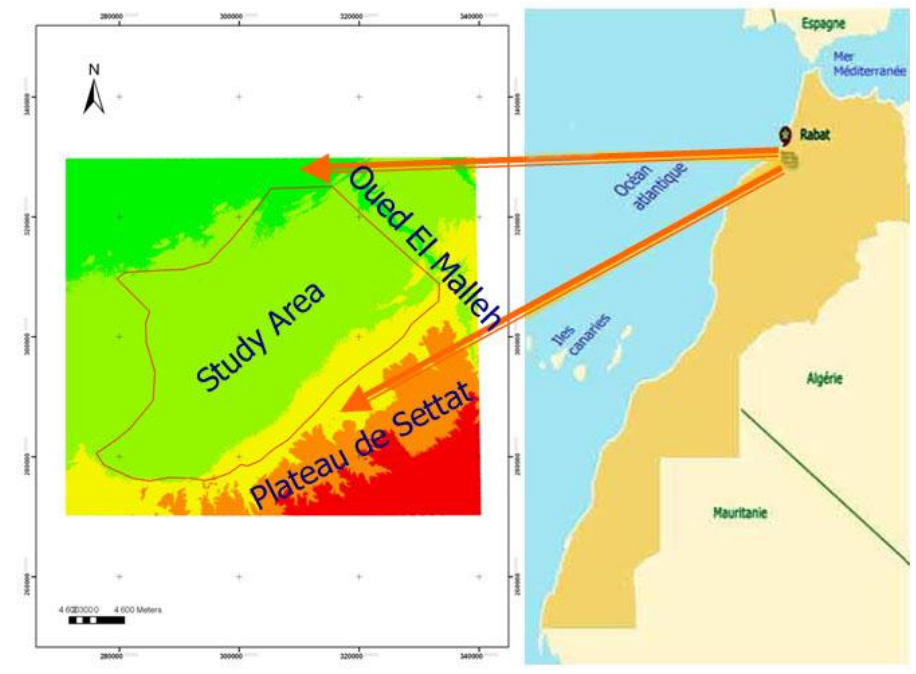

Fig.1: study area

\section{STUDY METHODS}

\section{1- DRASTIC method}

The DRASTIC method, developed by the services of the U.S. Agency for the protection of the Environment USEPA, it is based on a weighting and indexing system of parameters [8], based on ratings and weights given to the criteria chosen to study, classify and represent in the horizontal plane; the protective role of the interface between water resources of the source of pollution. The drastic acronym corresponds to the initials of the seven factors determining the value of the vulnerability index: depth to water (D): depth of the aquifer; Recharge Net (R): effective recharge of the aquifer; aquifer media (A): The lithology of the aquifer; soil media (S): soil type; topography (T): topographic slope of the land; impact of vadose zone (I): Impact of the vadose zone (unsaturated zone); hydraulic conductivity of the aquifer (C): hydraulic conductivity of the aquifer. Table 1 shows the weight of each drastic parameter.

Table 1: Drastic parameters assigned weights

\begin{tabular}{|l|l|}
\hline Factor & Weight \\
\hline D Depth to top the of the Aquifer & 5 \\
\hline R Net Recharge & 4 \\
\hline A Aquifer Media & 3 \\
\hline S Soil Media & 2 \\
\hline T Topography & 1 \\
\hline I Impact of the Vadose Zone & 5 \\
\hline C Hydraulic Conductivity of the Aquifer & 3 \\
\hline
\end{tabular}

The vulnerability index drastic is calculated as the sum of the products of ratings by the weight of the corresponding parameters:

Drastic index $=(\operatorname{Dr} \times D w)+(\operatorname{Rr} \times R w)+(A r \times A w)+(\operatorname{Sr} \times S w)+(\operatorname{Tr} \times \operatorname{Tw})+(\operatorname{Ir} \times I w)+(C r \times C w)(1)$

Where D, R, A, S, T, I, and C are the Seven Parameters of the DRASTIC method, w is the weight of the parameter and $\mathrm{r}$ is the rating. The obtained index drastic values represent the extent of the aquifer hydrogeological vulnerability; they vary from 23 to 226 in the case of the standard version. The values obtained are grouped, according to [8], in five classes, each of which corresponds to a vulnerability degree (Table 2).

Table 2: Criteria for the vulnerability assessment in the DRASTIC method (ALLERAnd al, 1987).

\begin{tabular}{|l|l|}
\hline Degree of Vulnerability & Vulnerability Index \\
\hline very low & $<80$ \\
\hline Low & $80-120$ \\
\hline Average & $121-160$ \\
\hline High & $161-200$ \\
\hline Very high & $>200$ \\
\hline
\end{tabular}




\section{2- THE SINTACS METHOD}

The SINTACS method is derived from the DRASTIC method. It was developed in Italy in the early 1990s in order to adapt the mapping to a larger scale in view of the great diversity of hydrogeological Italy [810] .The parametric models like SINTACS belong to the point count system model group in which every factor has not only its own score but also an additional weight to reduce or amplify its importance during the analysis. The additional weight is set in relation to environmental characteristics, such as high dispersion phenomena from surface water bodies to groundwater or widespread pollution sources [11].The parameters characterization of vulnerability that were identified in this approach are the same as those of the DRASTIC method, or Italian: (S): Soggiacenza (depth of water); (I): Infiltrazione (infiltration); (N): Not Azione del Satoru(depending on the unsaturated zone); (T): Tipologia della Copertura (soil); (A): Carratteri Idrogeologici dell 'Acquifero (hydrogeological characteristics of the aquifer); (C): Conductivity Idraulica (conductivity hydraulic). (S): Acclività Della Topographica area (average slope of the topographic surface).Unlike DRASTIC, SINTACS the method enables the use, and at the same time in different cells (table3), the weighting factors vary according to the situations [12].The specificity of this method is that it offers five different scenarios. Table 4 shows the attributed Weights to parameters in the different scenarios.

Table.3: SINTAGS rating values for the various hydrogeological parameter settings.

\begin{tabular}{|c|c|c|c|c|c|c|c|}
\hline \multicolumn{2}{|c|}{ Water table depth (m) } & \multicolumn{2}{|c|}{$\begin{array}{l}\text { Effective infiltration } \\
(\mathrm{mm})\end{array}$} & \multicolumn{2}{|c|}{ Aquifer media } & \multicolumn{2}{|c|}{ Soil media } \\
\hline Interval & $\mathbf{R}$ & Interval & $\mathbf{R}$ & Interval & $\mathbf{R}$ & Interval & $\mathbf{R}$ \\
\hline $2.60-4.57$ & 9 & $0-50.8$ & 1 & Gneiss & 4 & Sandy loam & 6 \\
\hline $4.57-6.50$ & 7 & $50.8-101.6$ & 3 & Sandstone & 3 & Clay loam & 3 \\
\hline & & $101.6-103.12$ & 6 & & & Non- shrinking & 1 \\
\hline Interval & $\mathbf{R}$ & Interval & $\mathbf{R}$ & Interval & $\mathbf{R}$ & & \\
\hline $0-2$ & 10 & Confining layer & 1 & $0.45-4.89$ & 1 & & \\
\hline $2-6$ & 9 & Silt/ clay & 3 & $4.89-8.3$ & 2 & & \\
\hline$>18$ & 1 & Sand and gravel & 8 & & & & \\
\hline
\end{tabular}

Table.4: Weights attributed to parameters in the different scenarios of the SINTACS method.

\begin{tabular}{|c|c|c|c|c|c|}
\hline $\begin{array}{l}\text { Scenario } \\
\text { parameter }\end{array}$ & $\begin{array}{l}\text { Normal } \\
\text { Impact }\end{array}$ & Severe Impact & $\begin{array}{l}\text { Important } \\
\text { Drainage }\end{array}$ & Karsts & cracked land \\
\hline S & $\mathbf{5}$ & $\mathbf{5}$ & $\mathbf{4}$ & $\mathbf{2}$ & $\mathbf{3}$ \\
\hline $\mathbf{I}$ & $\mathbf{4}$ & $\mathbf{5}$ & $\mathbf{4}$ & $\mathbf{5}$ & $\mathbf{3}$ \\
\hline $\mathbf{N}$ & $\mathbf{5}$ & $\mathbf{4}$ & $\mathbf{4}$ & $\mathbf{1}$ & $\mathbf{3}$ \\
\hline $\mathbf{T}$ & $\mathbf{4}$ & $\mathbf{5}$ & $\mathbf{2}$ & $\mathbf{3}$ & $\mathbf{4}$ \\
\hline $\mathbf{A}$ & $\mathbf{3}$ & $\mathbf{3}$ & $\mathbf{5}$ & $\mathbf{5}$ & $\mathbf{4}$ \\
\hline $\mathbf{C}$ & $\mathbf{3}$ & $\mathbf{2}$ & $\mathbf{5}$ & $\mathbf{5}$ & $\mathbf{5}$ \\
\hline S & $\mathbf{2}$ & $\mathbf{2}$ & $\mathbf{2}$ & $\mathbf{5}$ & $\mathbf{4}$ \\
\hline
\end{tabular}

Four vulnerability classes can be identified according to the values of the vulnerability indices (Table 5).

Table.5: Criteria for the vulnerability assessment in the SINTACS method.

\begin{tabular}{|l|l|}
\hline Degree of Vulnerability & Vulnerability Index \\
\hline Low & $<106$ \\
\hline Average & $106-186$ \\
\hline High & $186-210$ \\
\hline Very high & $>200$ \\
\hline
\end{tabular}

\section{RESULTS AND DISCUSSIONS}

1. Drastic settings and the aquifer vulnerability

- Depth of groundwater (D): has been developed by the interpolation of data on the water level. The interpolation is performed by the ordinary kriging method.

- $\square$ Recharge rate: The values of this parameter are acquired by the application of the Thiessen polygons on the data of effective rainfall.

- $\square$ The Aquifer media: The development of the matrix map "aquifer media" has been based, essentially, on the interpretation and the correlation between drilling in the study area.

- The Soil media: The study area map "Soil media" has been developed by the digitalisation of the national soil map, conducted by the Department of Agriculture and the Agricultural Development. This map shows a dominance of Clay textures and loam-Clay. 
- Topography: The matrix slope map is carried out from the digital model of terrain SRTM (Ftp://e0srp01u.ecs.nasa.gov).

- The Impact of the vadose zone: The evaluation process of the impact parameter of the vadose zone is based on the interpretation of the lithological drilling slices. The correlation shows that the unsaturated zone is constituted essentially by the clayey facies, sand and gravel.

- The hydraulic Conductivity of the aquifer: This map has been developed by the digitalisation of the hydraulic conductivity map of (ABHBC, 2012).

All the maps are classified; depending on the rating system of the DRASTIC method (Table 2). The figure 2 represents the classified maps.

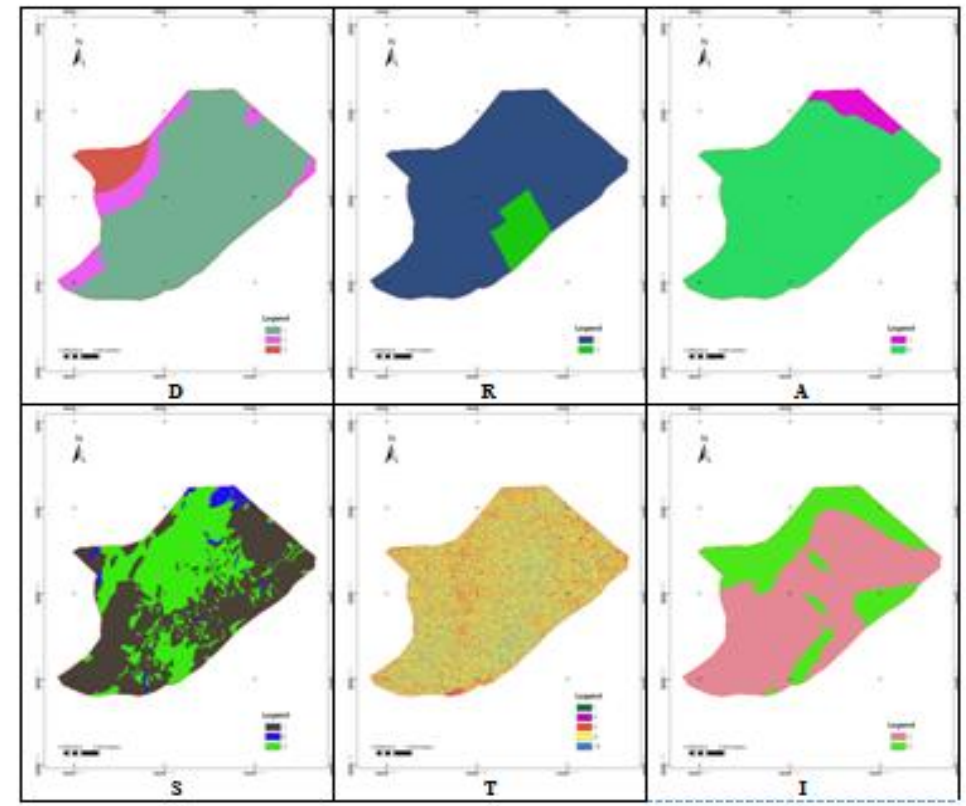

Fig.2: DRASTIC classified maps of Berrechid Aquifer

The obtained drastic map of Berrechid aquifer is the following (Fig 3), it shows 3 vulnerability classes: very low, low and medium with respective surfaces of (802, 767 and $1.85 \mathrm{~km} 2)$ (Table 6 and Fig.4).

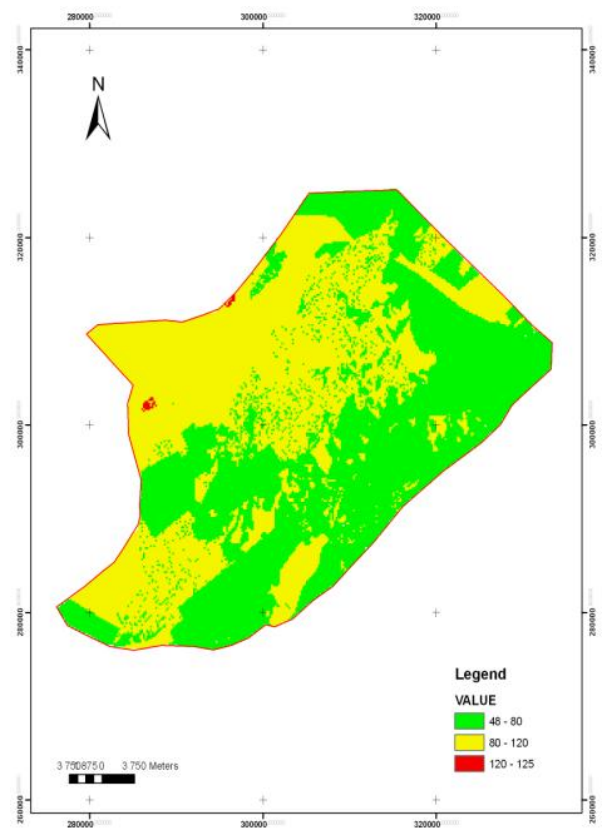

Fig.3: Drastic map of Berrechid Aquifer 
Table 6 : DRASTIC map statistics

\begin{tabular}{|l|l|l|}
\hline Degree of Vulnerability & Vulnerability Index & Area $\left(\mathrm{km}^{2}\right)$ \\
\hline Very low & $<80$ & 801,13 \\
\hline Low & $80-120$ & 766,71 \\
\hline average & $120-125$ & 1,8125 \\
\hline \multicolumn{2}{|c|}{ Area (km2) } \\
\hline \multicolumn{1}{|c|}{ average; 1,81} \\
\hline
\end{tabular}

Fig.4 : DRASTIC map statistics

\section{Drastic settings and the aquifer vulnerability}

The figure 5 represents the classified maps according to the SINTACS method.

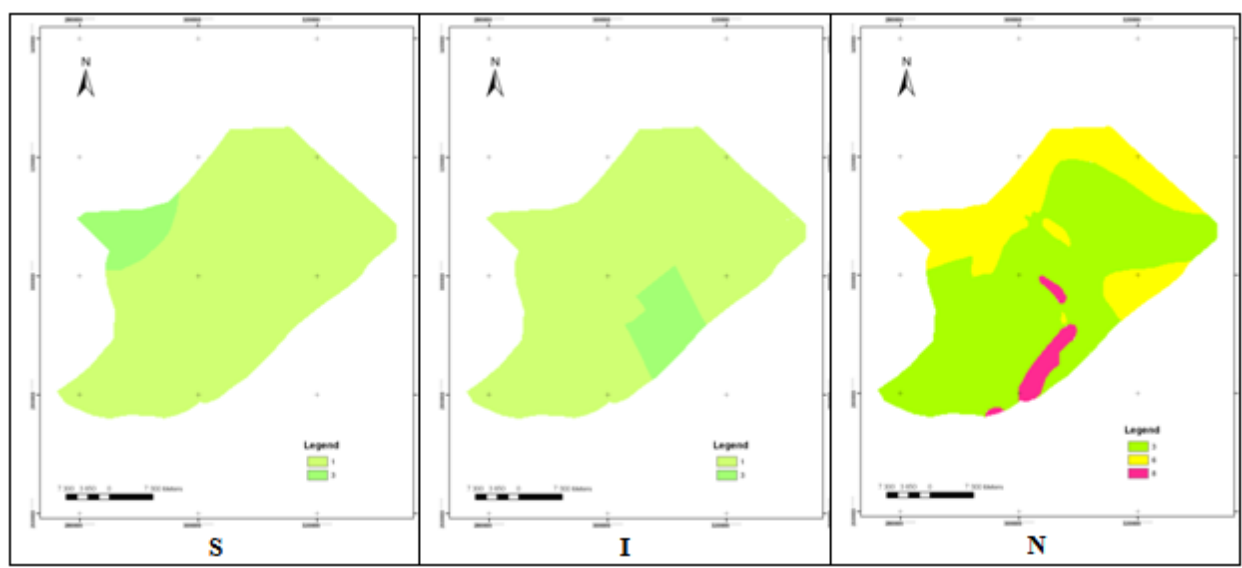

Fig.5: SINTACS classified maps of Berrechid Aquifer

The obtained SINTACS map of Berrechid aquifer is the following (Fig.6), it shows 2 classes of vulnerability: low and medium with respective surfaces of (1445.13 and 122.56 km2) (Table 7 and Fig.7).

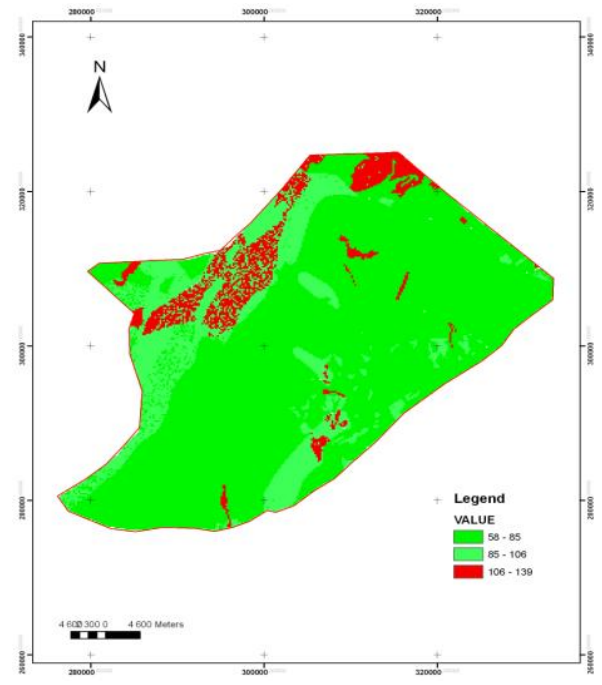


Fig.6: SINTACS map of Berrechid Aquifer

Table 7: SINTACS statistics

\begin{tabular}{|l|l|l|}
\hline & & \\
\hline Low & $<106$ & 1445,13 \\
\hline Average & $106-139$ & 122,56 \\
\hline
\end{tabular}

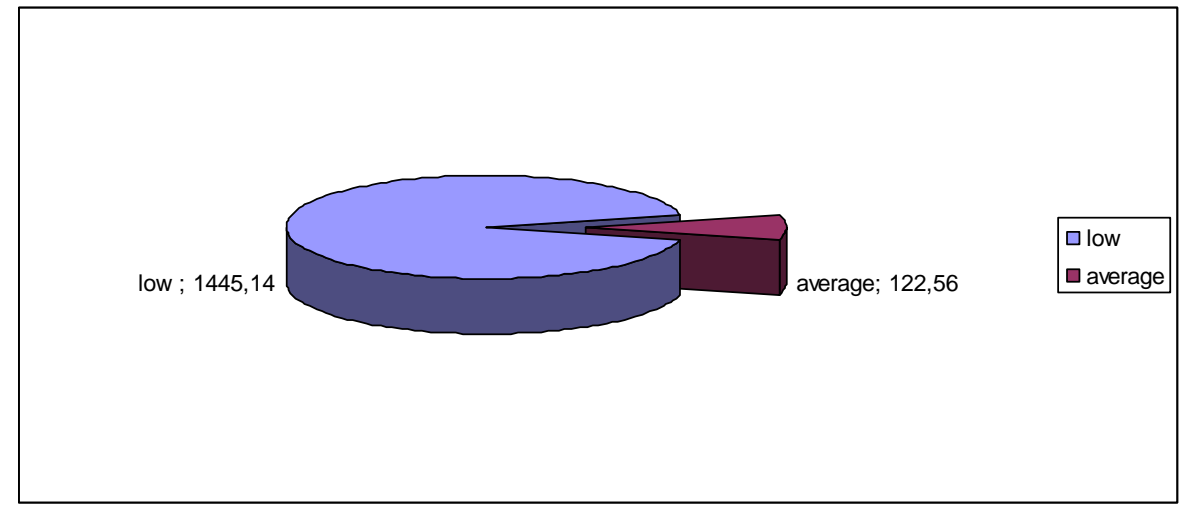

Fig.7: DRASTIC map statistics

\section{Sensitivity of the drastic Model}

Table 8 shows the summary data statistics of the seven parameters used to calculate the index drastic in the Berrechid plain. The analysis of the averages shows that the greatest risk of groundwater contamination of the plain of Berrechid is favoured by the parameters "topography, Aquifer media and hydraulic conductivity" (whose averages are respectively: 8.51, 571 and 4.70). However the parameters «soil and unsaturated zone» participate with a moderate risk (averages is 4.46 and 3.96), and the parameters Depth of groundwater and recharge promote a low risk (medium: 1.26 and 1.17).

The coefficient of variation shows that the great contribution to variations in the index of vulnerability is due to the parameter «soil» (CV: $87.44 \%)$. The parameters "hydraulic conductivity, recharge, depth of the groundwater and unsaturated zone" show an average contribution (CV: $70.64 \%, 47.86 \%, 46.03 \%$ and $35.35 \%$ ) however the aquifer and topography represent a contribution to the variation of the index of vulnerability medium to low (CV: 20.32 and 20.09).

Table 8: the summary data statistics of the DRASTIC parameters

\begin{tabular}{|l|l|l|l|l|l|l|l|}
\hline & & & & & & & \\
\hline Min & 1 & 1 & 1 & 1 & 1 & 3 & 1 \\
\hline Max & 3 & 3 & 6 & 9 & 10 & 6 & 10 \\
\hline Average & 1.26 & 1.17 & 5.71 & 4.46 & 8.51 & 3.96 & 4.70 \\
\hline SD & 0.58 & 0.56 & 1.16 & 3.90 & 1.71 & 1.40 & 3.32 \\
\hline CV & $46.03 \%$ & $47.86 \%$ & $20.32 \%$ & $87.44 \%$ & $20.09 \%$ & $35.35 \%$ & $70.64 \%$ \\
\hline
\end{tabular}

\section{Sensitivity of the SINTACS Model}

Table 9 shows the summary data statistics of the seven parameters used to calculate the index SINTACS in the Berrechid plain. The analysis of the averages shows that the greatest risk of groundwater contamination of the plain of Berrechid is favoured by the parameters "S, and $\mathbf{A}$ " (whose averages are respectively: 9.37 and 7.54). However the parameters «N and $\mathbf{T} »$ participate with a moderate risk (averages is 4.03 and 2.07), and the parameters "I, S and C" promote a low risk (average: 1.17, 1.14 and 1).

The coefficient of variation shows that the great contribution to variations in the index of vulnerability is due to the parameter «T» $(\mathrm{CV}: 75.85 \%)$. The parameters "I, $\mathbf{S}$ and $\mathbf{N}$ " show an average contribution $(\mathrm{CV}: 47.86 \%$, $44.74 \%$ and $38.21 \%$ ) however the parameters "A, $\mathbf{S}$ and $\mathbf{C}$ " represent a contribution to the variation of the index of vulnerability medium to low (CV: $17.90,11.95 \%$ and $0.00 \%)$.

Table 9: the summary data statistics of the SINTACS parameters

\begin{tabular}{|l|l|l|l|l|l|l|l|}
\hline & & & & & & \\
\hline Min & 1 & 1 & 3 & 1 & 3 & 1 & 1 \\
\hline Max & 3 & 3 & 8 & 9 & 8 & 1 & 10 \\
\hline Average & 1.14 & 1.17 & 4.03 & 2.07 & 7.54 & 1 & 9.37 \\
\hline
\end{tabular}




\begin{tabular}{|l|l|l|l|l|l|l|l|}
\hline SD & 0.51 & 0.56 & 1.54 & 1.57 & 1.35 & 0 & 1.12 \\
\hline CV & $44.74 \%$ & $47.86 \%$ & $38.21 \%$ & $75.85 \%$ & $17.90 \%$ & $0.00 \%$ & $11.95 \%$ \\
\hline
\end{tabular}

\section{Validation of the obtained maps}

Any developed vulnerability map is tested and validated by the measurement and analysis of chemical data of groundwater [13 -15]. The validity of the vulnerability assessment to pollution by DRASTIC and SINTACS methods in the case of this study has been tested by the pollution by nitrates in the water. So we compare the distribution of nitrate in groundwater and the distribution of vulnerability classes. The Figure 8 shows the map of the nitrate distribution in Berrechid groundwater [16]. In comparing the two maps: drastic and SINTACS, we find that the SINTACS method gives the best results: with a average vulnerability surface more important than that obtained according to the DRASTIC method in the north and north west, these areas are characterized by elevated levels of nitrate. These areas are characterized by low slopes, low depth of the Plan of water and the nature of the rock formations permeable. While the areas with vulnerability very low occupy the borders $\mathrm{NE}$ and $\mathrm{E}$ of the study area. These areas are characterized by a low permeability and the nature lithological little permeable "clay", offering to the aquifer a natural protection.

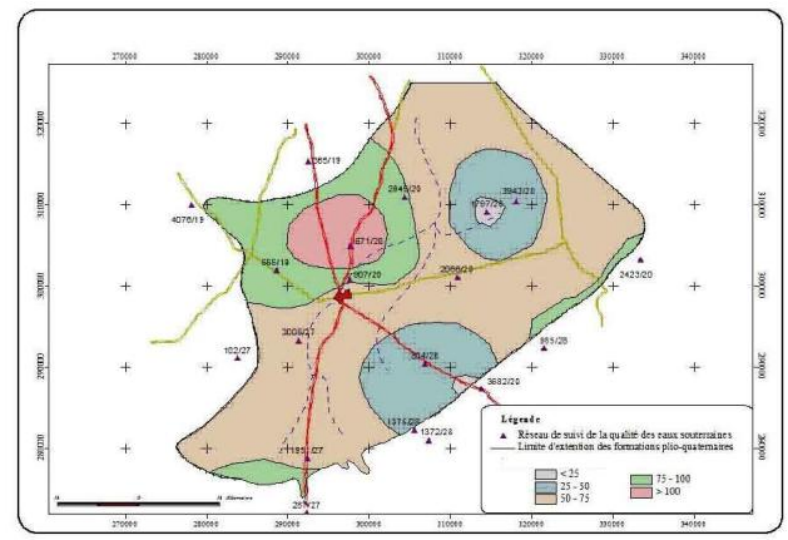

Fig.8: Map of distribution of nitrates in Berrechid groundwater (ABHCB)

\section{CONCLUSION}

In this study we attempted to assess the vulnerability of the Berrechid aquifer and to identify and classify vulnerable and non-vulnerable areas for contamination in order to provide zoning for groundwater protection and Implementation of effective strategies for groundwater management. We have used GIS for this purpose through the radical method. Indeed, GIS has provided an efficient environment for analysis and a high capacity for handling large quantities of spatial data. The seven parameters of each model were constructed, classified and coded using the GIS tool and its characteristics. The comparison of the vulnerability maps to pollution obtained using the DRASTIC and SINTACS methods shows that the closest results are those resulting from the SINTACS method. Berrechid Groundwater is polluted by high values of nitrates due to several phenomena: the discharge of solid and liquid waste from industry, domestic, and also by the use of large quantities of fertilizer in agriculture. This study produced a very important tool for management and development because it gives full details on the groundwater vulnerability; it provides decision support to local authorities to ensure sustainable protection of this resource.

\section{REFERENCES}

[1]. Aboulouafa, M., Taouil, H., \& Ibn Ahmed, S. (2016). Assessment of groundwater vulnerability and sensitivity to pollution in Berrechid plain, using drastic model, American journal of Engineering Research (AJER), Volume-5, Issue-2, pp-10-20

[2]. R. Hazan and L. Mouillard, « Notice hydrogéologique de la plaine de Berrechid ».

[3]. Ruhard, J.P. (1975). Chaouia et plaine de Berrechid. Ressources en eau du Maroc. Serve. Géol. Rabat. Maroc. II, $\mathrm{N}^{\circ} 231$.

[4]. L'Agence du Bassin Hydraulique du Bouregreg et de la Chaouia (ABHBC), (2015). Etat de la qualité des ressources en eau.

[5]. DAURIAC F., DESHAYES M., GILLON D., ROGER J.-M., (2001). Suivi de la teneur en eau de la végétation méditerranéenne par télédétection. Application au risque de feu de forêt. Colloque SIRNAT 2001 (Systèmes d'Information pour les Risques Naturels), Sophia Antipolis, 6-7 décembre 2001, 10 p.

[6]. B.ROY \& D.BOUYOUSSOU. (1993). „Méthodes multicritères d'aide à la décision „, Economica PARIS 
[7]. Aboulouafa, M., Taouil, H., \& Ahmed, S. I. (2016). Mapping and Assessment of Soil Loss in Berrechid Plain Using a Gis And the Universal Soil Loss Equation (Usle). American journal of Engineering Research (AJER), Volume-5, Issue-3, pp-184-190

[8]. Aller L, JH Lehr, R Petty, T Bennett. (1987). DRASTIC: A standardized system for evaluating groundwater pollution potential using hydrogeological settings, Jour. Geol. Soc. of India. 29, pp. 23-37.

[9]. Civita M (1990). The vulnerability evaluation of aquifers to pollution. Proc 1st Con. Nat. "Protection and Management of Groundwater: Methodologies, Technologies and Objectives', Marano sul Panaro. pp.3986.

[10]. Civita M, De Maio M, Vigna B (1999). A GIS Methodology for evaluation active aquifer recharge. Proceedings of the 3rd nationalist convention on the protection and management of groundwater in the third millennium. Papers of applied geology. pp. 291-303.

[11]. KUISI, M.A., EL-NAQA, A. and HAMMOURI, N., 2006, Vulnerability mapping of shallow groundwater aquifer using SINTACS model in the Jordan Valley area, Jordan. Environmental Geology, 50, pp. 645-650.

[12]. Khemmoudj. K, (2014). Assessment of the vulnerability of an aquifer by DRASTIC and SYNTACS methods: Aquifer of Bazer -Geult Zerga area (northeast Algeria).pp(170-178)

[13]. H .Elfarrak (2014) Development of Vulnerability through the DRASTIC Method and Geographic Information System (GIS) (Case Groundwater of Berrchid), Morocco.

[14]. J. P. Jourda, K. J. Kouamé, M. G. Adja, S. K. Deh, A. T. Anani, A. T. Effini and J. Biémi, (2017) "Evaluation du Degré de Protection des Eaux Souterraines: Vulnérabilité à la Pollution de la Nappe de Bonoua (Sud-est de la Côte d'Ivoire) par la méthode DRASTIC," Par la Méthode DRASTIC. Session Environnement/Eau.

[15]. M. H. Hamza, A. Added, R. Rodriguez, S. Abdeljaoued and A. Ben Mammou, (2007). "A GIS based DRASTIC Vulnerability and Net Recharge Reassessment in an Aquifer of a Semi arid region (MetlineRas Jebel-Raf Raf Aquifer, Northern Tunisia," Journal of Environmental Management, Vol. 84, No. 1, pp. 12-19.

[16]. L’Agence du Bassin Hydraulique du Bouregreg ET de la Chaouia (ABHBC) contrat de la nappe (2013). 